\title{
INSTITUTE OF PERSONNEL MANAGEMENT
}

W ITH an attendance of some eight hundred members representing central and local government departments, industrial organizations, universities and other educational institutions from Britain and overseas, the annual conference of the Institute of Personnel Management took place at Harrogate during October 9-11. The theme was personnel management and technological change; and the conference was opened by C. H. Broadhead, a director of the Imperial Tobacco Co., Ltd., who carried out a wide-ranging survey of the growth, development and possible extension of personnel management in British industry. In this review, Broadhead emphasized the continuing need for recognizing the employee as an individual in his own right, and for the specialist personnel managers constantly to act so that general management never forgets its personnel function when there is the risk of subordinating the individual to the organization.

Then followed five sectional meetings during one of which comparisons were made between the progress of technological education in the United States, the U.S.S.R. and Great Britain. From his investigations Dr. G. Tolley, research manager of Allied Iron Founders, Ltd., suggested that there is every indica. tion that the demand for trained engineers in Russia is now being satisfied by numbers currently graduating from full-time courses; it is probable that attention will now be concentrated upon the fulfilment of other objectives, for example, education in special technologies, such as in the chemical process industries. In addition, the existing facilities for training technicians and skilled workers, already organized on a vast scale, may be increased and supplemented. Although a great deal is known about the content of scientific and technological courses given in Russian educational institutions, little is known about Russian education for management and labour relations, and the key to the development of Russian society may lie here, rather than in the growth of science or technology as such. "Already, however, a largely Victorian society is rumbling rapidly on the move, and we would do well to remember that the huge reservoir of highly educated persons now being created in Russia will probably be capable of demanding something more than heavy industry."

At another meeting Miss $\mathrm{J}$. Woodward and $\mathrm{T}$. Lupton, of the University of Manchester, discussed the contribution of industrial sociology to management education. In the development of management theory Miss Woodward indicated that the early period was dominated by pioneers who sought to establish management theory on scientific foundations and to formulate laws which would describe phenomena and explain the relationship between cause and effect in an industrial situation. Classical management theory is based on the philosophy of the one best way, and is deterministic in that it assumes that this one best way can be found by suitable study and research. In the past twenty years a move away from determinism has taken place. It is now generally accepted that similar administrative expedients can, and often do, produce considerable variations in results. In the narrower field of the planning and control of manufacturing operations, tools of operational research are being used to isolate the variables linked with these varia. tions. In the wider field of administrative behaviour, the move away from determinism has had less satisfactory results. There is a tendency to fall back on phraseology and proverbs and to assume that all variations are dependent solely on personality differences. The essential step in the establishment of a scientifically valid theory of management is the isolation and understanding of the variables in industrial situations. The most important facet of the investigations made by Miss Woodward in southeast Essex was not its challenge to classical management theory but its attempt to isolate one major variable in industrial situations from that of the actual techniques of production and to link this variable with observed variations in results. The information collected suggested that the techniques of a particular system of production impose demands on the human boings involved which limit and con. trol their behaviour.

Studies of the behaviour of workers by Lupton and his colleagues have led to conclusions similar to those reached by Woodward in her studies of management. The behaviour of workers is influenced by such factors as the productive methods employed, the related administrative structures of the firm, and market factors. In the past five years six detailed investigations of the behaviour of workers, using participant observation as the main research technique, have been carried out. In only one of these, carried out among male engineering workers, was there behaviour resembling that found in the Bank Wiring Room of the Hawthorne experiments, that is to say, group controls over the level of output and earnings. In some workshops evidence was found of individualism and competitive striving as the normal mode of behaviour, while in others there was an absence of a clearly defined code of conduct relating to output and earnings. Further research, taking fuller account of other factors, may lead to a situational theory of workers' behaviour which challenges many of the naïve sociological and psychological generalizations which pass as 'principles of human relations'.

In a discussion on government policy and company pension schemes for manual workers, V. R. Jackson, head of the Pensions Department, Unilever, Ltd., argued that employers would be unwise to 'contract out' of the graduated part of the State scheme which comes into force in April 1961. Against this, H. A. R. Barnett, a consulting actuæry, provided many reasons why employers should seize the opportunity to contract out.

The effect of equal pay on employment policies was examined by R. E. Griffiths, secretary to the Local Authorities' Conditions of Service Advisory Board. During the past five years equal pay has been introduced in the public services-including the Civil Service, the Local Government Service (including 
teachers), the nationalized industries, and the Health Service. Progress to man's rate of pay is, by instalments, to be completed in 1961.

From observations of the workings of equal pay, Jackson has concluded that, where there is freedom of choice, equal pay will encourage the appointment and promotion of men in preference to women; equal pay may mean less security for women in times of recession; where women form a substantial proportion of an employed group, as in the basic teaching grade, equal pay-rates will tend to be lower than for a solely male group, and scales may be longer. This will tend to drive men out of the group; the increase in the inequity of living standards between family men and single women without dependants receiving equal pay will probably necessitate some form of additional family allowances; and, finally, equal pay raises costs, and may force reductions in the numbers employed.

The concluding session was concerned with the interaction of operational research and personnel management. The organization and mode of working of an operational research department was described by Stafford Beer, head of the Department of Operational Research and Cybernetics, United Steel Companies, Ltd.

Operational research involves the application of the methods of science to operations, whether military, industrial economic, or of any other kind. It has to consider systems of men and machines, materials and money; it is concerned with the regulation of these systems, with their decision processes, with their operation for maximum profit or minimum wastage or optimum use of resources. Operational research deals with the strategy of operations: not from general concepts of what management 'ought' to be like, but from the scientific principles of quantification, of inference, of experimental and analytical technique.

Beer suggested that operational research was relevant to personnel management for three reasons. First, the task of managing operational research itself has been little considered by those responsible for personnel management. Most big companies in most industries employ operational research workers. These departments have to be organized, and their organization poses very difficult and unusual problems. The departments have to be fitted into the existing organization of the parent company or institution on a routine basis, and this also raises difficult issues. The growth of this activity has been rapid : it has led to an extremely intractable education and training problem in which few educationists have taken an interest. Staff are still particularly hard to find, and their suitability hard to assess. By informing themselves about the topic of operational research, about its capabilities, its organization and its staff, personnel managers would put themselves in a position to help both their companies and the operational research movement to achieve a properly organized and integrated activity.

Socondly, an operational research discussion of its own organization is of possible interest to personnel managers in another way. Organization is itself a typical subject of operational research study. In discussing the organization appropriate for operational research, points of interest for other kinds of organization may well be uncovered. The third point of relevance for personnel managers is the most important. Operational research can certainly be applied to personnel problems themselves. Personnel management could well commission studies in its own field of problems, when operational research would be found cepable of handling systems of exclusively human components. A good demonstra. tion of it in practice was given by L. T. Wilkins and Herbert Mannheim in their scientific attack on operational problems of the Borstal system. This has been hailed as the greatest advance in penology for twenty-five years.

The application of operational research to the understanding of human beings was considered by Prof. R. W. Revans, of the Department of Industrial Administration, University of Manchester. The human problems of industry are not so much with individuals as with groups. There might be profit in trying to understand the nature of authority, the ways it is exercised and the effects that it produces. The highly complex relationships perceived as authority, namely, the willingness of one man to do what another man wants him to do, may change their nature simply by being discussed. To that extent these problems do not have the objectivity that is often regarded as a necessary attribute of scientific material. There is no evidence, for example, to suggest that if one hundred men sit down and talk about the law of gravity for a week, the nature of the law is in any way changed. But if one hundred men sit down and talk for a week about a strike in a motor factory, it is likely to make the strike very much worse. There is a difference between the study of the social problems of industry and the study of the problems of classical science, but it does not deny the validity of observational methods in the study of society.

A particular study of authority arises out of some work that Revans and his colleagues were invited to do at hospitals in the region of Manchester. The immediate and urgent problem was-and still isthat there are nothing like enough nurses in our hospitals and there seems little promise of obtaining substantially more.

An Indian student spent two years laboriously tracing the records of more than four thousand hospital employees in five comparable hospitals in Lancashire, and in 1958 brought out the first conclusions. Srivastava showed that, first, the voluntary wastage of nursing students during their three years of training differed significantly from one hospital to another and that, secondly, the hospitals with high voluntary wastage-rates among students had high wastage-rates among other members of staff, such as cleaners, auxiliary nurses, ward sisters and even the matrons themselves. All popular explanations, such as early marriage, the attractions of better paid jobs in the same town, even the decay of modern youth to-day, were shown to be illusory. There appears to be about every hospital some factor of cohesion which determines whether anybody in its service will want to stay there or not, and this cohesion (or lack of it) extends up to the matron and down to the most junior nurses.

It appeared that this factor of cohesion might have other manifestations. If the staff were prepared to stay at one hospital twice as long on average as at another, one might expect this to be reflected in some effect upon the patients. Srivastava found that tho order in which the hospitals were placed for their ability to retain their student nurses was precisely the same as the order in which they were placed for the 'length of patient stay'. Srivastava chose cases which were, between hospitals, most directly 
comparable. For this he chose cases of appendicitis. During the year 1958, considerably more than a thousand people were operated upon for this complaint in five hospitals ; a perfect fit was found between the percentage of student wastage and the average length of patient stay. Average wastage ranged from 38 per cent in the hospital best able to retain its students to 65 per cent in the worst; the mean length of stay for appendicitis ranged from $7 \cdot 5$ days to $11 \cdot 9$. A significant concordance between all staff wastage and all clinical conditions examined was also found. Altogether, more than 5,000 cases of appendicitis, hernia, colectomy, partial gastrectomy, eystoscopy, asthma, bronchitis and pneumonia and head injuries have been examined; making allowance for differences between hospitals that have convalescent homes and those that have not, the hospital that can keep its staff longer can also deal with its patients more quickly.

This now law reinforces confidence in the organic concept of the hospital; it suggests that staff and patients seem to be influenced to the same extent. The source of this influence must be sought in the wards themselves. It has already been found that, in the hospitals with the high wastage rates, the student nurses particularly, but other nursing staff as well, complain of a general uncertainty about their work; their instructions often appear to be haphazard and it seems difficult to get decisions out of their committees. "A student nurse of 19 may not be afraid of hard work, does not complain about her money or the plainness of her diet, but is terrified of being put into situations which she does not understand because they have not been explained." A feeling of helpless ignorance is more corrosive of morale than the fear of any official rebuke which such ignorance may bring down. The girl who becomes a nurse has enough concern for her work to fortify her against the terrors of authority as such. But if she feels that she cannot carry her responsibility to her patients because she does not know what to do, she will in the end withdraw from an impossible situation, very often with regret.

Revans also drew upon later investigations to examine whether or not the character of the individual hospital is tied up with resistances to the friendly exchange of views and arrival at decisions. $\mathrm{H}_{\mathrm{e}}$ suggested that this inquiry into the nature of authority will lead to new fields of inquiry and understanding.

\section{ALKALI ION DETERMINATIONS BY MEANS OF GLASS ELECTRODES}

$\mathrm{T}$ HE possibility of measuring alkali ion concentrations in aqueous solutions by means of an electrode potential offers many advantages over other physical methods such as the flame photometer. Since the publication in 1957 by Eisenman, Rudin and Casby ${ }^{1}$ on the sensitivity to sodium and potassium ions of glass electrodes made from sodium aluminosilicate glasses, interest in the subject has been growing rapidly and a Research Colloquium was held in the Department of Glass Technology, University of Sheffield, on May 6 to discuss the theory of the electrodes and some possible fields of application.

Dr. G. Mattock (Electronic Instruments, Ltd.) reminded those present that the development of glasses responsive to alkali metal ions has always been a possibility from the early recognition in studies on $p \mathrm{H}$ of glasses showing 'alkaline error'. In broad terms, the first requirement is to develop a glass which has a large alkali metal ion error. There seems to be no fundamental difference between glasses functioning for $p \mathrm{H}$ and those for alkali metal ions: all electrode glasses show some sensitivity both to hydrogen and to alkali metal ions, even, apparently, to other singly charged cations such as ammonium. The chief problem in devising compositions is the achievement of selectivity to a given ion in the presence of others.

Lengyel and Blum ${ }^{2}$, Nikolskii and his co-workers ${ }^{3}$, and Eisenman, Rudin and Casby ${ }^{1}$ have all shown the importance of aluminium and/or boron in promoting alkali metal response when substituted for silica in a glass. The last-named workers have carried out a very exhaustive study on the $\mathrm{Na}_{2} \mathrm{O}-\mathrm{Al}_{2} \mathrm{O}_{3}-\mathrm{SiO}_{2}$ ternary system and have worked out extensive theories to cover the whole field of specific interactions at surfaces ${ }^{4}$. The fundamental importance of ionexchange is accepted, the theory considering the factors affecting electrostatic attraction between ions in solution and the glass surface. The relative selectivity of glass response to different cations is qualitatively accounted for in terms of the competing effects of negative fields due to residual charges on oxygen ions (caused by the isomorphic introduction of trivalent aluminium or boron into the tetravalent silicon framework) and the hydrating tendencies of the bare cations. At low negative field-strengths on the lattice the ability to dehydrate a cation is weak, so that the order of selectivity (considered to depend on the effective radii of the ions) is related to the order of size of hydrated radii. At high field-strengths, this order can be reversed; and with intermediate fields, intermediate orders can be obtained-but significantly only eleven are theoretically predictable and only eleven have been found. These orders are :

(1) $\mathrm{Cs}, \mathrm{Rb}, \mathrm{K}, \mathrm{Na}, \mathrm{Li}$
(2) Rb, Cs, K, Na, $\mathrm{Li}$
(3) $\mathrm{Rb}, \mathrm{K}, \mathrm{Cs}, \mathrm{Na}, \mathrm{Li}$
(4) K, Rb, Cs, Na, Li
(5) K, Rb, Na, Cs, Li
(6) K, Rb, Na, Li, Cs

(7) $\mathrm{K}, \mathrm{Na}, \mathrm{Rb}, \mathrm{Li}, \mathrm{Cs}$

(8) $\mathrm{Na}, \mathrm{K}, \mathrm{Rb}, \mathrm{Li}, \mathrm{Cs}$

(10) $\mathrm{Na}, \mathrm{K}, \mathrm{Li}, \mathrm{K}, \mathrm{Rb}, \mathrm{Cs}$

(11) $\mathrm{Li}, \mathrm{Na}, \mathrm{K}, \mathrm{Rb}, \mathrm{Cs}$

Eisenman and Rudin are shortly to publish a full description of their treatment.

Dr. Matlock had been principally concerned up to now with studying the inductive effects of different. polarizing substituents on the selectivity properties of glasses, and with obtaining easily workable glasses ; a disadvantage of the original compositions of Eisenman, Rudin and Casby having been their extremely high softening points, making them difficult to fabricate into electrodes. Collaboration with Dr. Eisenman has now enabled development to be made on the basis of the Eisenman and Rudin theory, giving both ease of workability and improved selectivity. Glasses responsive to potassium have 